\title{
CIRCULAÇÃO E DESENVOLVIMENTO REGIONAL: UMA AVALIAÇÃO DOS IMPACTOS DO PLANO NACIONAL DE LOGÍSTICA E TRANSPORTES NO CENTRO-OESTE BRASILEIRO
}

\author{
Alex Tristão de Santana ${ }^{1}$ \\ Eguimar Felício Chaveiro ${ }^{2}$ \\ Emerson Martins ${ }^{3}$ \\ João Batista de Deus ${ }^{4}$
}

Resumo: $O$ presente artigo tem como objetivo analisar o Plano Nacional de Logística e Transportes (PNLT) e o repertório teórico-metodológico que orienta a abordagem das políticas de planejamento no Brasil. Com foco nas propostas intervencionistas no Centro-Oeste brasileiro, procura-se dialogar com uma questão problematizadora: quais os sentidos político-territoriais presentes no discurso do PNLT e seus possíveis impactos na dinâmica econômica e social do Cerrado? Um pressuposto analítico serviu de esteio a toda estrutura narrativa: não se pode desprezar no estudo das políticas de planejamento a relação com a formação socioespacial do país, tão pouco com os atores envolvidos nas tarefas de concepção e execução dos planos; isto porque uma estratégia de planificação sempre atende determinados interesses de uso e apropriação do território, orquestrados por atores políticos e econômicos com alto poder de articulação nas esferas de decisão. Nestes termos, a metodologia adotada contemplou a revisão bibliográfica e a análise documental.

Palavras-chave: planejamento; PNLT; dinâmica territorial; cerrado brasileiro.

\section{CIRCULATION AND REGIONAL DEVELOPMENT: AN EVALUATION OF THE IMPACTS OF THE NATIONAL LOGISTICS AND TRANSPORT PLAN IN THE CENTRAL WEST BRAZILIAN}

Abstract: This article aims to analyze the National Logistics and Transport Plan (PNLT) and the theoretical-methodological repertoire that guides the approach to planning policies in Brazil. Focusing on the interventionist proposals in the Brazilian Center-West, we seek to dialogue with a problematizing question: what are the political-territorial meanings present in PNLT's discourse and its possible impacts on

\footnotetext{
${ }^{1}$ Professor do Instituto Federal Goiano, Campus Trindade (IF Goiano, Camus Trindade). Doutor pelo Instituto de Estudos Socioambientais, da Universidade Federal de Goiás (IESA/UFG). santanageoufg@ gmail.com.

${ }^{2}$ Professor do Programa de Pós-Graduação em Geografia, do Instituto de Estudos Socioambientais, da Universidade Federal de Goiás (IESA/UFG). eguimar@ hotmail.com.

${ }^{3}$ Professor da Rede Estadual de Educação do Estado de Goiás. Mestre pelo Instituto de Estudos Socioambientais, da Universidade Federal de Goiás (IESA/UFG). geomiguelao@ gmail.com.

${ }^{4}$ Professor do Programa de Pós-Graduação em Geografia, do Instituto de Estudos Socioambientais, da Universidade Federal de Goiás (IESA/UFG). deus.joão@gmail.com.

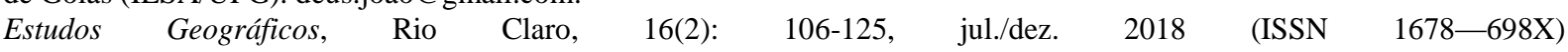

http://www.periodicos.rc.biblioteca.unesp.br/index.php/estgeo 
the economic and social dynamics of the Cerrado? An analytical assumption served as a basis for all narrative structure: one can not ignore the relationship with the socio-spatial formation of the country in the study of planning policies, as well as with the actors involved in the design and execution of the plans; This is because a planning strategy always meets certain interests of land use and appropriation, orchestrated by political and economic actors with high power of articulation in the decision-making spheres. In these terms, the adopted methodology contemplated the bibliographical revision and the documentary analysis.

Keywords: planning; PNLT; territorial dynamics; brazilian cerrado.

\section{INTRODUÇÃO}

O Plano Nacional de Logística de Transportes versa sobre um arranjo espacial que desperta interesse de diferentes ordens, estratégicas, econômicas, geopolíticas, regionais: os territórios do Cerrado brasileiro. A proposta deste trabalho consiste em fazer uma análise do PNLT apresentando sua composição estrutural, seus lastros com outros planos, bem como suas lógicas, anteriores e atuais.

Os espaços considerados no PNLT, permeados de compleições logísticas, respondem nominalmente por Vetores Logísticos, estes, em número de sete no território brasileiro. Ao receberem investimentos nos diversos modais de transportes até a década de 2030 dariam novo dinamismo na circulação e no desenvolvimento diretamente em escalas regionais, e, indiretamente, em escalas globais. Isso, em letras, diminuiria as desigualdades sociais com positivos rebatimentos de caráter prático, principalmente nos custos, no equilíbrio da infraestrutura dos fixos e fluxos, e no meio ambiente em escala nacional (PNLT, 2011).

Estamos falando do discricionário jogo capitalista que estruturou os rumos do modal de transporte no território brasileiro ao longo da história que esteve sucessivamente guiado por corporações do território, com vistas a atender aos interesses dos grupos hegemônicos vinculados ao sentido de globalização; trata-se, a saber, que o modelo de desenvolvimento que faça uso da logística, recria, no mundo do Cerrado, as contradições de uma economia desigual e combinada.

Mesmo apresentando em sua estrutura teórica propostas de planejamento que almejam ampla participação de secretarias como a de Política Nacional de Transportes (SPNT), do Ministério dos Transportes, da Confederação da Agricultura e Pecuária do Brasil (CNA), da Confederação Nacional da Indústria (CNI), da Confederação Nacional dos Trabalhadores em Transportes (CNTT), da Confederação Nacional do Transporte (CNT), das representações sociais e institucionais de interesses inclusivos com vistas à sustentabilidade e promoção da justiça social, considera-se ser difícil tais feitos, visto o modo como se distribui os investimentos em cada um dos vetores conformam-se com a presença forte de grupos hegemônicos principalmente nos centros exportadores das commodities.

No geral, o panorama do compromisso público/privado, previsto no PNLT, poderá até promover a fluidez (em centros agroexportadores principalmente), mas a metodologia dos investimentos de forma seletiva e excludente perpetrará a manutenção das desigualdades socioregionais que, desconfiamos, não será atenuada. A tecnicidade prevista nos investimentos não elimina a opacidade

Estudos Geográficos, Rio Claro, 16(2): $106-125, \quad$ jul./dez. $2018 \quad$ (ISSN 1678 -698X) http://www.periodicos.rc.biblioteca.unesp.br/index.php/estgeo 
espacial de adjacências regionais cujas direções não se conectam aos espaços luminosos que são vetores dos investimentos, ao contrário, desconfia-se de uma derrogação dos poucos objetos técnicos dos espaços já deprimidos.

Ao debruçarmos o olhar geográfico sobre as nuances que em essência descortinam os investimentos do PNLT junto aos Vetores logísticos, pretende-se verificar as intencionalidades intrínsecas ao seu pavimento teórico que aparece ladrilhado de termos e evocações politicamente corretas quanto à saídas para os atrasos socioespaciais do país. A premissa interrogativa posta no trabalho enseja revelar quais as reais prioridades e consonâncias que se pode abstrair da metodologia do PNLT.

Iniciar-se-á o primeiro tópico dissertando sobre o planejamento no Brasil e o regime de fluxos ao logo do tempo cujos objetivos foram segundo autores como Castillo (2011), Rocha Neto (2013), Lima (2015), Bastos (2016), Araújo (1999), Vainer (1995), Maia Gomes (1993), Rezende (2010), lanni (1996) superar as dificuldades recorrentes da sociedade brasileira frente à logística de transporte no país. $\mathrm{Na}$ sequência, ainda com auxílio dos autores acima, far-se-á uma apresentação dos investimentos em infraestrutura previstos no PNLT, bem como de outros aspectos gerais, com cuidadosa interpretação do papel central do Estado, das corporações e dos atores hegemônicos que se revelarem na leitura.

Sem se abster do conhecimento sobre a formação da sociedade brasileira, e os motivos pelos quais emergiram os problemas que desafiam a política de planejamento como solução para diminuição das desigualdades sociais, o trabalho será concluído com um diagnóstico crítico da dimensão política, participativa e inclusiva que o PNLT revela em seu arcabouço teórico - prático frente às atuais demandas socioespaciais de seus Vetores de investimentos.

A discussão apresentada soma-se ao trabalho de diferentes pesquisadores em torno do projeto de pesquisa "Novas determinações produtivas, regionais e urbanas na área do Cerrado brasileiro: uma avaliação sobre os efeitos das obras de infraestrutura rodoferroviárias na integração regional", também conhecido como Projeto Pró-Integração, vinculado ao edital nำ5/2018, da Coordenação de Aperfeiçoamento de Pessoal de Nível Superior (CAPES) e do Ministério da Integração. Executado em parceria entre a Universidade Federal de Goiás (UFG), a Pontifícia Universidade Católica de Goiás (PUC-GO) e Universidade de Campinas (UNICAMP), o projeto tem permitido intercambio teórico-metodológico entre as equipes de pesquisadores e resultados relevantes do ponto de vista da interpretação da dinâmica dos principais eixos de circulação do Cerrado brasileiro.

\section{O PLANEJAMENTO NO BRASIL E O REGIME DE FLUXOS}

Os estudos de planejamento no Brasil são constituídos, com frequência, por duas vias: uma de sentido pragmático, cujo objetivo é apontar rumos para o desenvolvimento econômico e social ao mesmo tempo que supõe, com as operações de desenvolvimento, superar os problemas crônicos da sociedade brasileira. Outra via esmera a sua reflexão na interpretação da formação da sociedade brasileira curvando a análise ao entendimento do papel do Estado e dos denominados atores hegemônicos. Trata-se, nesta via, de mostrar a coincidência de os mesmos atores que falam e executam planos de desenvolvimento serem os responsáveis pelos problemas econômicos e sociais e pela cultura política no qual o planejamento visa superar.

Estudos Geográficos, Rio Claro, 16(2): 106-125, jul./dez. $2018 \quad$ (ISSN 1678-698X) http://www.periodicos.rc.biblioteca.unesp.br/index.php/estgeo 
A primeira tendência institui uma concepção de planejamento baseada nos aparatos técnicos; na organização de indicadores e na capacidade de diagnosticar problemas. Ela é responsável também por definir modelos, muitos dos quais, importados do mundo rico. Essa perspectiva esboça bases teóricas e paradigmáticas do planejamento e patenteia uma visão de país: o planejamento é um recurso que pode definir e equilibrar os rumos de uma economia liberal. Nesta ótica, não cabe o planejamento aproximar-se da política, mas ser ancoradouro da gestão.

A segunda tendência, compreendida e destacada por autores como Florestam Fernandes (1975) e Octávio lanni (1996), reformula a ótica do planejamento: cabe pensar a política e os seus atores, como por exemplo, o Estado, as classes dominantes e outros atores que criam os planos, desde a sua concepção, o seu lume ideológico até a sua implantação.

Nesta tendência, o planejamento, em qualquer escala, seja na escala da macroeconomia ou o que se denomina planejamento territorial, ou na escala regional, municipal e setorial, está ligado e incluído nas direções ideológicas do Estado e na sua batalha para legitimar sua forma de poder. A dimensão técnica - e dos saberes implicados nas concepções de planos -, dessa maneira, está subjugada pela direção política e ideológica que lhe torna possível e a legitima.

As duas tendências certamente podem ser mescladas, interseccionadas e oferecer pistas para criação de outras concepções. Contudo, ao evidenciá-las poderse-ia vislumbrar uma compreensão de ordem teórica: pensar o planejamento no Brasil é pensar o Brasil que planeja. Ou seja, exige-se pensar a formação da sociedade brasileira, portanto o seu passado do qual emergiram os problemas que desafiam a política de planejamento e o planejamento como fator político como, por exemplo, a desigualdade social; a dependência econômica dos países ricos; a transferência de tecnologia; a segregação social de grupos não hegemonizados; a estrutura desigual do território; as potências e os limites dos diferentes biomas; a cultura política; a política fiscal; a organização federativa, a dimensão social do espaço agrário e da estrutura fundiária; a urbanização e a concentração urbana; o modelo produtivo e a geração do emprego; a distribuição da população no território e os seus vínculos com os setores da educação e da saúde.

Especificamente Octávio lanni (1996), na sua obra considerada clássica Estado e Planejamento Econômico no Brasil (1930-1970), funda uma análise do planejamento no Brasil por meio da relação entre o Estado e a economia buscando compreender o grau de conexão entre poder econômico e poder político. Ao mostrar que a partir de 1930, o Estado, sob injunção externa, passa a interferir na economia interna, o autor constrói uma periodização, a saber:

primeira fase - 1930-45: políticas econômicas nacionalistas;

> segunda fase - 1946-50: políticas econômicas liberais;

$>$ terceira fase - 1951-54: desenvolvimento e capitalismo nacional;

$>$ quarta fase - 1955-60: industrialização e interdependência;

> quinta fase - 1961-1964: Estado e economia na crise do Desenvolvimento;

> sexta fase - 1964-1970 - interdependência e modernização.

Ao sabor dessa periodização, o autor menciona desdobramentos políticos, econômicos e sociais do processo, como a incrementação de uma burocracia denominada "tecnoestrutura estatal"; o conflito e a incongruência entre o poder

Estudos Geográficos, Rio Claro, 16(2): $\quad 106-125, \quad$ jul./dez. $2018 \quad$ (ISSN $\quad$ 1678-698X) http://www.periodicos.rc.biblioteca.unesp.br/index.php/estgeo 
legislativo e a hipertrofia do executivo. E mostra o cerne do sentido do processo na qual sintetiza uma oscilação entre duas tendências de desenvolvimento: de um lado a elaboração de políticas, planos e ações direcionadas para a construção de um capitalismo nacional e, noutra perspectiva, uma associação, ou uma estratégia de subordinação estratégica ao capitalismo mundial denominada de "estratégia de desenvolvimento dependente".

A interpretação do planejamento no Brasil feita por lanni (1996) sugere pontos básicos e decisivos para, após 1970, especialmente de 1980 até o presente momento, pensar o seu logro aglutinado ao modo pelo qual a sociedade brasileira se desenvolveu. Três pontos podem ser destacados: o conteúdo e a forma do Estado e sua intervenção na economia; a relação com a economia internacional, isto é, a inspiração externa; e a dimensão territorial das intervenções e dos planos nas diferentes fases.

A implementação dos PNDs, especialmente o primeiro PLANO NACIONAL DE DESENVOLVIMENTO - 1972-74 - dá início a uma série de intervenções territoriais e de organização burocrática e legal, decisivos para criar uma matriz econômica para o país mediante uma infraestrutura e de uma logística que enunciasse os esplendores de um país rumo à modernização. Todavia, na década de 1980, as mudanças políticas, o grande apelo popular de mudanças na cultura política ligadas à crise mundial, alteraria a conformação do planejamento. Rezende (2010, p. 16) avalia esta fase explicando que,

"Na década de 1980, o funcionamento do sistema de planejamento sofreu duros golpes. A segunda crise do petróleo (1979-1980) e o esgotamento das possibilidades de o Estado sustentar o ritmo de investimentos registrado no período anterior, em face do agravamento dos desequilíbrios externos e internos, associado ao enfraquecimento do Poder Executivo durante o período de transição para a democracia, contribuíram para reduzir sua capacidade de articulação das decisões governamentais. O III PND (1980-1985) cumpriu a formalidade exigida pelo supracitado dispositivo legal, mas a falta de unidade no comando da política econômica, com visões diferentes esposadas pelos Ministérios da Fazenda e do Planejamento a respeito de como enfrentar a crise contribuiu para que ele fosse, na prática, abandonado".

Esse processo sofreu alteração com a constituição de 1988. Os acontecimentos políticos em torno da luta pela Anistia no começo da década; as campanhas pelas eleições diretas; a demanda pela participação popular; a crítica ao modelo autoritário e à dependência econômica, são acontecimentos que conduziram o planejamento à dimensão política e participativa, alterando o sentido burocrático e a crença técnica apenas.

O quadro apetecível para a organização popular, para as manifestações e para a edificação de um processo crítico, contudo contextualizado numa crise do sistema, apontava para uma vertente plural das ações e concepções de gestão e planificação. O alto índice da inflação, a instabilidade monetária, o endividamento externo, a pouca capacidade de financiamento do Estado seriam os desafios do governo que se instalou na década de 1990.

O relativo sucesso na estabilização monetária e a elaboração do plano Plurianual para o período 1996-1999 geraram as condições para que o planejamento voltasse a intentar as ações macroeconômicas e estipulassem concepções ligadas à

Estudos Geográficos, Rio Claro, 16(2): $\quad 106-125, \quad$ jul./dez. $2018 \quad$ (ISSN $\quad$ 1678-698X) http://www.periodicos.rc.biblioteca.unesp.br/index.php/estgeo 
formação da sociedade brasileira. Ideias como a construção de um Estado eficiente, moderno e mínimo; redução dos desequilíbrios regionais e sociais; incrementação da modernização produtiva; e inserção competitiva no mundo alçaram os pontos de uma postura neoliberal na relação entre o Estado e o território, bem como da política de governo com a iniciativa privada.

A política de privatização de estatais como a Companhia Vale do Rio Doce, de ações da Petrobrás e mais de dezenas de empresas, não cumpriu o propósito de eliminar as despesas, sanear o desequilíbrio fiscal. E ainda: a política salarial restritiva juntamente com um plano de acerto com as antigas oligarquias, mantiveram o país num grau de dependência, sem dar conta de elaborar uma cultura de planejamento eficiente e equilibrada.

A ascensão do Governo Lula no poder político do país indicou uma mudança paradigmática no planejamento: a ordem era criar um modelo de desenvolvimento implicado na solução dos problemas sociais. A necessidade de operar as mudanças institucionais e elaborar programas sociais tinham como objetivo fazer convergir 0 crescimento econômico - um apelo da acumulação capitalista de modelo financeirizada - com distribuição de renda e inclusão social.

Neste quadro seria providente e necessário retomar os planos setoriais que se articulavam com a perspectiva macroeconômica, como o setor de energia, o setor industrial, agrícola e da infraestrutura e logística. Além disso, era necessário que o Estado ajudasse a incrementar o mercado interno, a transferência de renda e políticas de moradia, de emprego, de saúde e de expansão do ensino universitário.

Várias ações foram implementadas, o que gerou mudanças territoriais evidentes, como construção de portos; construção de rodovias, ferrovias; melhora de aeroportos; transferência de renda; programas de inclusão; expansão da universidade pública; construção de plataformas tecnológicas, formando o que alguns autores chamam "neodesenvolvimentismo brasileiro". Contudo, foram mantidas a cultura política e o modelo concentrador da renda advindo do estilo e do conteúdo da modernização brasileira. Araújo (1999, p.153) ao analisar a desigualdade como o cerne do enfrentamento do planejamento, analisa assim:

\begin{abstract}
"as formas pelas quais se materializaram essas desigualdades ao longo do século $X X$, mas provavelmente se observará 0 aumento da heterogeneidade intrarregional, como supõe Pacheco (PACHECO, 1998), posto que o próprio estilo de crescimento da economia mundial é profundamente assimétrico e aos atores globais interessam apenas os espaços competitivos do Brasil. Espaços identificados a partir de seus interesses privados e não dos interesses do Brasil. Os países para esses agentes são meras "plataformas de operação". O quadro futuro tende a ser mais complexo que no passado recente, posto que em antigas áreas dinâmicas podem surgir bolsões de pobreza, áreas antes pouco exploradas podem ser "descobertas e dinamizadas" e áreas dominantemente pobres podem abrigar "focos dinâmicos" restritos.
\end{abstract}

Diante da análise da autora, entende-se que o desafio do planejamento no Brasil atual se coloca no sentido de enfrentar o que autores como Vainer (1995) e Maia Gomes (1993), veem como problemas centrais da sociedade brasileira atualizados pelas tendências contemporâneas do mercado.

Essa realidade gera como consequência outro quadro: os territórios dinâmicos passam a atrair setores de zonas excluídas, sofrendo rapidamente 0

Estudos Geográficos, Rio Claro, 16(2): $\quad 106-125, \quad$ jul./dez. $2018 \quad$ (ISSN $\quad$ 1678-698X) http://www.periodicos.rc.biblioteca.unesp.br/index.php/estgeo 
abalo do desemprego, de problemas sociais como a violência urbana e outros; e as regiões não competitivas tendem a aumentar o fosso da desigualdade regional incrementada pela desigualdade social.

Ao fazer uma síntese do quadro atual Araújo (1999, p.157) aborda que,

Nos dias atuais, a quebra do comando hegemônico do Sudeste pela maior abertura a articulações internacionais, os diversos fatores que estimulam a desconcentração das bases produtivas (fortalecendo especializações regionais dispersas no território e geradoras de focos dinâmicos mesmo em antigas áreas tidas apenas como regiãoproblema) e a descentralização de políticas públicas são elementos que criam OPORTUNIDADE para mudar a abordagem e fundar uma nova Política Nacional de Desenvolvimento Regional no Brasil. Por tudo que já se analisou no presente trabalho, é mais que nunca oportuno superar as "choradeiras" regionalistas de um lado e as posturas discriminatórias de outro para pensar e agir no Brasil HETEROGÊNEO e DIVERSIFICADO. Para tratar como positivo, como potencialidade (e não como problema) a crescente diferenciação interna das diversas macrorregiões do País.

Sua análise apresenta pistas para ler o Brasil atual - e para se pensar o planejamento já realizado e o que deverá ser feito.

\section{PLANO NACIONAL DE LOGÍSTICA E TRANSPORTE: ASPECTOS GERAIS}

No rol das políticas de planejamento atuais o PNLT se inclui como instrumento representativo dos desejos de modernização da matriz de transportes brasileira por parte de setores políticos e econômicos com forte atuação nos espaços de comando do país. Em linhas gerais, este plano reforça a importância da retomada do planejamento do setor de transportes, sob a visão estratégica de longo prazo. Em sua primeira versão (2007) apresenta simulações para o horizonte temporal até 2023, e na sua terceira versão (2011), dilata este período até 2031.

Embasado em metodologia científica voltada à modelagem e avaliação de viabilidade econômica dos projetos de infraestrutura de transporte, o documento pretende orientar as intervenções públicas e privadas e subsidiar as demandas de integração, desenvolvimento e superação das desigualdades regionais. Por isso, serve de base para elaboração dos Planos Plurianuais (PPA) e definição de projetos do Programa de Aceleração do Crescimento (PAC), implantados durante os governos dos presidentes Luiz Inácio Lula da Silva (2001-2009) e Dilma Rousseff (2010-2015).

O PNLT propõe maior equilíbrio na matriz de transporte do país mediante a "racionalização do uso do modal rodoviário no atendimento de demandas com maior capilaridade e no complemento dos demais modais". O conceito de logística também aparece como novidade e indica uma mudança de paradigma na concepção das políticas públicas de transportes. Há um entendimento no sentido de se trabalhar para a maior eficiência, racionalidade e redução dos custos com a movimentação de cargas no país, o que evidencia o esforço de modernização e competitividade com as matrizes de transporte de países mais desenvolvidos.

Estudos Geográficos, Rio Claro, 16(2): 106-125, jul./dez. $2018 \quad$ (ISSN 1678-698X) http://www.periodicos.rc.biblioteca.unesp.br/index.php/estgeo 
O Relatório Final do PNLT de 2012 foi organizado pelo Consórcio LogitGistran, consultoria especializada em engenharia de transportes, sob supervisão da Secretaria de Política Nacional de Transportes (SPNT), do Ministério dos Transportes. Contou ainda com a colaboração de outros ministérios e também da Confederação da Agricultura e Pecuária do Brasil (CNA), da Confederação Nacional da Indústria (CNI), da Confederação Nacional dos Trabalhadores em Transportes (CNTT) e da Confederação Nacional do Transporte (CNT).

A participação e colaboração de diferentes atores demonstra a tentativa de tratamento mais integrado das políticas públicas de transportes pelos órgãos de planejamento. Todavia, também revela o jogo de interesses em torno da definição dos investimentos e da concepção da política estratégica do setor no Brasil. Isso permite indagar até que ponto o PNLT apresenta uma visão integrada do território nacional ou atende lógicas econômicas particulares, setoriais, e seletivamente localizadas. A ausência do Ministério da Integração Nacional na elaboração do plano, por exemplo, reforça esta preocupação.

No PNLT de 2012 é possível verificar os aspectos fundamentais e gerais do plano, apresentados a seguir no quadro 01 . Cinco ideias centrais sintetizam os propósitos do documento, assim como a concepção político-territorial que sustentou sua elaboração. Logística, multimodalidade, ganhos socioambientais, desenvolvimento regional e competitividade aparecem como palavras-chave e indicam as intencionalidades.

A primeira ideia central versa a racionalização da atividade logística, indicando que este conceito é incorporado, com muita expectativa, pelos gestores públicos, embora não exista uma definição clara e fundamentada deste termo no documento (BASTOS, 2016). Tomando como base apenas o que está exporto, depreende-se que os formuladores corroboram que o conceito de logística é potencialmente eficaz para uma maior racionalização das atividades produtivas e de consumo nas diferentes regiões brasileiras.

\section{Quadro 01 - Objetivos gerais do PNLT (2012)}

\begin{tabular}{|l|l|}
\hline 1 & $\begin{array}{l}\text { Racionalização da atividade logística nas diversas regiões brasileiras, com } \\
\text { ordenamento do território a partir das potencialidades de produção e consumo }\end{array}$ \\
\hline 2 & $\begin{array}{l}\text { Fomento à multimodalidade, com aproveitamento maximizado das vantagens } \\
\text { de cada modal de transporte, valorizando as estruturas e redes atuais }\end{array}$ \\
\hline 3 & $\begin{array}{l}\text { Promoção de ganhos socioambientais, com a utilização das vantagens } \\
\text { microrregionais e com redução dos impactos na emissão de poluentes }\end{array}$ \\
\hline 4 & $\begin{array}{l}\text { Busca permanente do desenvolvimento econômico regional, com geração de } \\
\text { empregos e de riqueza }\end{array}$ \\
\hline 5 & $\begin{array}{l}\text { Aumento da competitividade das empresas e das regiões, onde o transporte } \\
\text { evolui de uma condição periférica para se constituir em elemento fundamental } \\
\text { de manutenção da competitividade sustentada no longo prazo }\end{array}$ \\
\hline
\end{tabular}
Fonte: PNLT (2012, p. 45).

Org.: A. T. de Santana (2016).

A segunda ideia central aborda o fomento à multimodalidade nos transportes. Como foi colocado acima, há uma constatação de um desequilíbrio na matriz de transportes brasileira, com claro favorecimento do modal rodoviário. Os especialistas consideram isso prejudicial ao país, devido a forte dependência da exportação de commodities, que percorrerem longas distâncias entre as áreas

Estudos Geográficos, Rio Claro, 16(2): $\quad 106-125, \quad$ jul./dez. $2018 \quad$ (ISSN $1678-698 X)$ http://www.periodicos.rc.biblioteca.unesp.br/index.php/estgeo 
produtoras e os portos, encarecendo os custos finais do produto. Por isso, ampliar a participação dos outros modais na matriz de transportes brasileira consiste em objetivo central dos novos investimentos.

A terceira ideia chave trata da promoção de ganhos socioambientais, almejados tanto no âmbito das singularidades microrregionais como na possibilidade de redução dos gases poluentes a partir da utilização de outros modais. Apesar de concordar com a real redução dos gases poluentes a partir da utilização de meios de transportes poupadores de combustíveis, sobressai a dúvida quanto aos possíveis ganhos sociambientais nas escalas microrregionais, tendo em vista o elevado nível de degradação socioambiental das atividades econômicas mais dinâmicas no território brasileiro, como o agronegócio e a mineração, por exemplo.

A quarta ideia central reafirma o desenvolvimento regional como estratégia a ser perseguida pela política de transportes. De fato, os investimentos na infraestrutura de transportes promovem forte impacto nas dinâmicas regionais, pois envolve a mobilidade do trabalho para execução das obras, a ativação do mercado com a aquisição dos materiais e equipamentos a serem utilizados e promove significativamente a especulação fundiária nas regiões impactadas. Todavia, com base na leitura do documento e na análise da metodologia que orienta a definição dos investimentos prioritários do PNLT, a abordagem volta-se, sobretudo para o fortalecimento de regiões competitivas, o que pode agravar as desigualdades regionais.

A problemática apontada acima dialoga também com a quinta ideia central do PNLT, que menciona a aumento da competitividade das empresas e das regiões por meio dos investimentos em transportes. Não se despreza aqui a relevância da infraestrutura de transportes para potencializar as condições de circulação e, consequentemente, o desenvolvimento regional. Porém, este objetivo sugere que o transporte tem papel fundamental numa economia em crescente processo de mundialização, pois torna-se condição basilar das empresas e regiões participarem do mercado mundial. Conforme sugere Araújo (1999), esta característica contribui muito na interpretação do fenômeno de integração seletiva dos lugares e estruturação das regiões competitivas, que colocam novos desafios ao planejamento territorial e/ou regional.

Com o propósito de atender uma perspectiva de longo prazo, o PNLT apresenta ações de natureza estruturante, materializadas em quatro propostas de projetos: aumento da eficiência produtiva em áreas consolidadas (AEP); indução ao desenvolvimento de áreas de expansão de fronteira agrícola e mineral (IDF); redução de desigualdades regionais em áreas deprimidas (RDR); integração regional sul-americana (IRS) detalhados no quadro 02.

Alguns aspectos dos projetos estruturantes do PNLT são pertinentes e contribuem para uma problematização dos objetivos gerais do documento. $O$ aumento da eficiência produtiva em áreas já consolidadas e a integração das frentes de expansão das fronteiras agrícola e mineral, por exemplo, são ações que visam, sobretudo, aumentar a competitividade de empresas e regiões, conforme os fundamentos analisados acima. Não há, todavia, uma relação muito clara entre estas ações e os projetos de redução de desigualdades regionais em áreas deprimidas. De acordo com as ponderações de Araújo (1999), uma preocupação é eminente: os possíveis impactos que o aumento da competitividade regional, via maior eficiência logística, poderá provocar em regiões dinâmicas e regiões

Estudos Geográficos, Rio Claro, 16(2): 106-125, jul./dez. $2018 \quad$ (ISSN 1678-698X) http://www.periodicos.rc.biblioteca.unesp.br/index.php/estgeo 
deprimidas, sobretudo levando ao aprofundamento do seu distanciamento, econômico, político e social.

\section{Quadro 02 - Tipos de projetos estruturantes do PNLT}

\begin{tabular}{|l|l|}
\hline $\begin{array}{l}\text { AEP - Aumento da } \\
\text { eficiência produtiva em } \\
\text { áreas consolidadas }\end{array}$ & $\begin{array}{l}\text { Projetos voltados a incrementar a eficiência do } \\
\text { abastecimento de insumos e do escoamento da produção } \\
\text { em áreas que ostentam maior grau de consolidação e de } \\
\text { desenvolvimento em sua estrutura produtiva. }\end{array}$ \\
\hline $\begin{array}{l}\text { IDF - Indução ao } \\
\text { desenvolvimento de áreas } \\
\text { de expansão de fronteira } \\
\text { agrícola e mineral }\end{array}$ & $\begin{array}{l}\text { Projetos para catalisar processos de expansão do } \\
\text { desenvolvimento em novas áreas de fronteira agrícola, em } \\
\text { especial no Centro-Oeste e em regiões de exploração de } \\
\text { riquezas minerais. }\end{array}$ \\
\hline $\begin{array}{l}\text { RDR - Redução de } \\
\text { desigualdades regionais em } \\
\text { áreas deprimidas }\end{array}$ & $\begin{array}{l}\text { Projetos para desenvolvimento em regiões que hoje } \\
\text { apresentam indicadores econômicos e sociais abaixo dos } \\
\text { valores médios nacionais, de forma a reduzir as } \\
\text { desigualdades em relação a outras áreas do País. }\end{array}$ \\
\hline $\begin{array}{l}\text { IRS - Integração regional } \\
\text { sul-americana }\end{array}$ & $\begin{array}{l}\text { Projetos para reforçar e consolidar o processo de } \\
\text { integração da infraestrutura na América do Sul, } \\
\text { possibilitando trocas comerciais, intercâmbio cultural e } \\
\text { social entre o Brasil e seus vizinhos. }\end{array}$ \\
\hline
\end{tabular}

Fonte: PNLT (2012, p. 47).

Org.: A. T. de Santana (2016).

Todas as ações elencadas anteriormente são organizadas a partir de uma perspectiva de ordenamento territorial denominada Vetores Logísticos. Segundo definição do próprio PNLT (2012, p. 32):

Os Vetores Logísticos são espaços territoriais brasileiros onde há uma dinâmica socioeconômica mais homogênea sob o ponto de vista de produções, de deslocamentos preponderantes nos acessos a mercados e exportação, de interesses comuns da sociedade, de patamares de capacidades tecnológicas e gerenciais e de problemas e restrições comuns, que podem convergir para a construção de um esforço conjunto de superação de entraves e desafios.

$\mathrm{Na}$ proposta de definição dos Vetores Logísticos as microrregiões homogêneas do IBGE foram utilizadas como referência de análise de um conjunto de fatores, tais como: similaridades socioeconômicas; perspectivas de integração e inter-relacionamento; custos de transportes em relação aos principais portos de carga do país; e impedâncias ambientais. Isso permitiu a elaboração de uma "nova proposta" de organização espacial do território brasileiro, de acordo com a perspectiva da política de transportes. Sete agrupamentos foram identificados: Amazônico, Centro-Norte, Nordeste Setentrional, Nordeste Meridional, Leste, Centro-Sudeste e Sul, conforme se vê na figura 01.

Estudos Geográficos, Rio Claro, 16(2): 106-125, jul./dez. $2018 \quad$ (ISSN 1678-698X) http://www.periodicos.rc.biblioteca.unesp.br/index.php/estgeo 


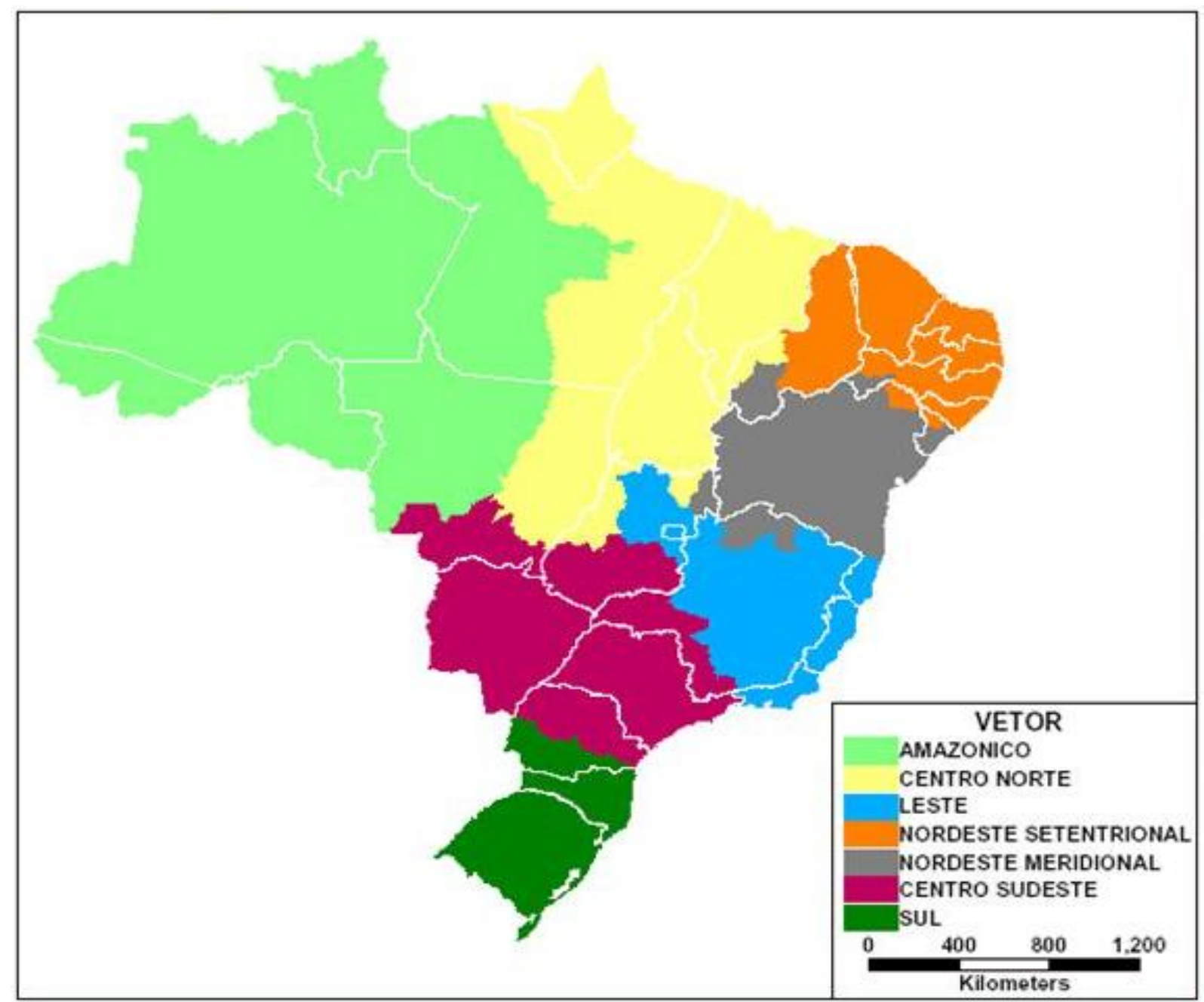

Figura 01 - Vetores Logísticos do Plano Nacional de Logística e Transportes (2011) Fonte: PNLT (2012).

A definição dos investimentos nos inúmeros projetos segue a orientação dos Vetores Logísticos. Atendem assim, a perspectiva de fortalecimento da nova proposta de regionalização. O critério de viabilidade econômica também é adotado por meio da Taxa Interna de Retorno Econômico (TIRE) dos investimentos, criando uma hierarquia em relação aos diferentes projetos avaliados.

Esta proposta de regionalização, apesar de apresentar-se como inovadora, segue uma perspectiva muito próxima aos corredores de exportação. Entre seus critérios definidores encontra-se a interligação com os principais portos de cargas do país e o favorecimento do escoamento dos produtos de maior de circulação no mercado externo. Isso levou alguns autores, como Castillo (2011), Rocha Neto (2013), Bastos (2016) entre outros, a verificar similaridades desta proposta com as antigas definições dos Eixos Nacionais de Desenvolvimento (ENIDs), dos "corredores de exportação", ou mesmo das "redes extrovertidas", presente no Brasil desde as capitanias hereditárias.

Após esta apresentação do PNLT, proceder-se-á com a análise dos seus impactos no Centro Oeste Brasileiro.

Estudos Geográficos, Rio Claro, 16(2): $\quad 106-125, \quad$ jul./dez. $2018 \quad$ (ISSN $\quad$ 1678-698X) http://www.periodicos.rc.biblioteca.unesp.br/index.php/estgeo 


\section{IMPACTOS DO PNLT NO CENTRO-OESTE BRASILEIRO}

Para a analise dos impactos do PNLT no Centro-Oeste brasileiro torna-se necessário uma avaliação dos investimentos planejados e a forma como eles foram elencados e hierarquizados a partir de uma proposta de viabilidade econômica que define quais são os projetos mais importantes. De acordo com Castillo (2011), Rocha Neto (2013), Lima (2015), e Bastos (2016) esta metodologia de análise dos projetos revela uma intencionalidade do PNLT de fortalecer a dinâmica dos complexos agroindustriais no Centro-Oeste brasileiro.

Um dado inicial é a previsão dos investimentos, que contempla três categorias de projetos: 1) aqueles inseridos no âmbito do Programa de Aceleração do Crescimento (PAC); 2) os projetos prioritários avaliados no PNLT; 3) os projetos sociopolíticos não avaliados no PNLT. Vale ressaltar que o portfólio disponível no PNLT contém apenas os projetos prioritários, os quais foram estudados detalhadamente a fim de definir sua viabilidade econômica.

Como é possível observar na tabela 01, o total de investimentos previstos no PNLT para infraestrutura de transportes aproxima-se de 424 bilhões de reais. Desse total, 142,4 bilhões integram o PAC, portanto não passaram pelo mesmo critério de avaliação dos projetos prioritários (muitos dos quais, inclusive, atenderam demandas sociopolíticas). Os projetos prioritários somam 75,4 bilhões de reais e foram avaliados criteriosamente pela metodologia utilizada pelos técnicos que elaboraram - PNLT. Tais projetos orientarão a ação dos agentes públicos e privados e possuem taxas de retorno econômico significativas. Já os projetos sociopolíticos e não avaliados somam 205,8 bilhões de reais, o que corresponde a 48,6\% do total de investimentos previstos. Como não há informações disponíveis sobre esses projetos (no documento analisado) e levando-se em consideração que o foco do estudo é o aumento da competitividade logística do país, fica a dúvida quanto à sua provável execução.

Tabela 01 - Investimentos considerados para os projetos do portfólio do PNLT 2012 (milhões de reais)

\begin{tabular}{|c|c|c|c|c|c|c|c|c|}
\hline Projetos & $\begin{array}{c}\text { Rodoviári } \\
0 \\
\end{array}$ & $\begin{array}{c}\text { Ferroviári } \\
0 \\
\end{array}$ & Hidroviário & $\begin{array}{c}\text { Dutoviári } \\
0 \\
\end{array}$ & $\begin{array}{c}\text { Terminai } \\
\mathbf{s} \\
\end{array}$ & $\begin{array}{c}\text { Aeroviári } \\
0 \\
\end{array}$ & $\begin{array}{c}\text { Portuári } \\
0\end{array}$ & Total \\
\hline PAC & 57.834 & 78.172 & 2.629 & - & 1.691 & 115 & 1.985 & $\begin{array}{c}142.42 \\
5\end{array}$ \\
\hline Prioritários & 30.761 & 39.402 & 5.301 & - & - & - & - & 75.464 \\
\hline $\begin{array}{l}\text { Sociopolítico } \\
\text { s e não } \\
\text { avaliados }\end{array}$ & 41.244 & 72.393 & 12.625 & 2.362 & 999 & 22.343 & 53.919 & $\begin{array}{c}205.88 \\
6\end{array}$ \\
\hline Total & 129.839 & 189.967 & 20.555 & 2.362 & 2.689 & 22.459 & 55.904 & $\begin{array}{c}423.77 \\
4\end{array}$ \\
\hline
\end{tabular}

Fonte: PNLT (2012).

Org.: A. T. de Santana (2016).

No âmbito dos investimentos nos projetos prioritários há uma distribuição nos diferentes Vetores Logísticos. Segundo dados do PNLT (2012) essa distribuição se dá da seguinte forma: Vetor Amazônico com 20\%; Vetor Centro Sudeste com 20\%; Vetor Leste com 13\%; Vetor Nordeste Meridional com 8\%; Vetor Nordeste Setentrional com 8\%; Vetor Sul com 24\%; Vetor Centro Norte com $7 \%$.

Estudos Geográficos, Rio $\quad$ Claro, $\quad 16(2): \quad 106-125, \quad$ jul./dez. $2018 \quad$ (ISSN 1678 -698X) http://www.periodicos.rc.biblioteca.unesp.br/index.php/estgeo 
A região Centro Oeste, por ter uma localização central no Brasil é recortada por cinco, dos sete, Vetores Logísticos, sendo eles: o Amazônico; o Centro Norte; o Nordeste Meridional; o Leste; e o Centro Sudeste (Figura 01). Portanto, é preciso fazer o levantamento dos investimentos previstos neste diferentes Vetores Logísticos para saber o valor ou o percentual destinado a esta região.

Antes de realizar tal procedimento, convém destacar que esse aspecto demonstra, por um lado, a posição estratégica do Centro Oeste na articulação dos fluxos no territorial nacional. Por outro lado, também revela as articulações históricas dos estados centroestinos com as diferentes regiões brasileiras, notadamente com o Sudeste e o Norte do País. Isso acaba privilegiando o Centro Oeste, uma vez que suas áreas mais dinâmicas economicamente foram inseridas nos Vetores Centro Sudeste e Amazônico, que concentram $40 \%$ dos investimentos prioritários previstos no PNLT.

Ao selecionar os projetos direcionados ao Centro Oeste verifica-se que o valor aproximado dos recursos previsto para a região é da ordem de 20 bilhões de reais. Esse valor corresponde a $26,5 \%$ dos investimentos dos projetos prioritários. Considera-se que o montante é significativo, tendo em vista que os Vetores logísticos Centro Norte, por exemplo, participou apenas com 7\% na divisão de recursos.

O detalhamento dos investimentos previstos por modais para o Centro Oeste também revela as intencionalidades do plano. Ainda de acordo com a tabela 02 é possível verificar que o modal ferroviário concentra mais de $50 \%$ dos investimentos, seguido pelo modal rodoviário $(29,8 \%)$ e hidroviário (14,6\%). Há um sentido geopolítico na priorização do modal ferroviário, uma vez que o PNLT pretende "equilibrar" a matriz de transporte de cargas do país. Outro aspecto é que as ferrovias constituem-se vias de escoamento alternativo rumo aos portos, com grande potencial de reduzir os custos com transportes e superar os "gargalos logísticos", termo bastante utilizado pela imprensa e pelos agentes do agronegócio.

\section{Tabela 02 - Investimentos considerados para os projetos prioritários do PNLT 2012 (milhões de reais)}

\begin{tabular}{ccccc}
\hline Projetos & Rodoviário & Ferroviário & Hidroviário & Total \\
Prioritários (total) & 30.761 & 39.402 & 5.301 & 75.464 \\
Centro-Oeste & 5.964 & 11.129 & 2.916 & 20.009 \\
\hline
\end{tabular}

Fonte: PNLT (2012).

Org.: A. T. de Santana (2016).

Todavia, ao analisar a quantidade de projetos e a extensão das obras ainda verifica-se a primazia do setor rodoviário. Ao todo são 17 projetos para o modal rodoviário, que chegam a $7.535 \mathrm{~km}$ de extensão; dois projetos para o moral hidroviário, com $3.100 \mathrm{~km}$ de extensão; e três projetos para o modal ferroviário com $1.975 \mathrm{~km}$ de extensão. Eles podem ser consultados nos quadros 03, 04 e 05.

Estudos Geográficos, Rio Claro, 16(2): 106-125, jul./dez. $2018 \quad$ (ISSN 1678 -698X) http://www.periodicos.rc.biblioteca.unesp.br/index.php/estgeo 


\section{Quadro 03 - Portfólio de projetos prioritários do modal rodoviário (PNLT-2012)}

\begin{tabular}{|c|c|c|c|c|c|c|c|}
\hline Modal & Vetores & Nome & Tipo & $\begin{array}{l}\text { Invest. } \\
\text { (R\$ mil) }\end{array}$ & $\begin{array}{l}\text { Ext. } \\
\text { (km) }\end{array}$ & TIRE & $\begin{array}{l}\text { Período } \\
\text { de } \\
\text { Implant. }\end{array}$ \\
\hline Rodoviário & Amazônico & $\begin{array}{c}\text { MT-322 (BR-080): } \\
\text { Bom Jesus do } \\
\text { Araguaia/MT a } \\
\text { Peixoto Azevedo/MT }\end{array}$ & Pavimentação & 316.649 & 176 & $\begin{array}{l}12 \mathrm{a} \\
16 \%\end{array}$ & Até 2015 \\
\hline Rodoviário & $\begin{array}{l}\text { Centro- } \\
\text { Norte }\end{array}$ & $\begin{array}{c}\text { BR-070: } \\
\text { Aragarças/GO }\end{array}$ & Pavimentação & 85.870 & 48 & $\begin{array}{c}8 \mathrm{a} \\
12 \% \\
\end{array}$ & Até 2015 \\
\hline Rodoviário & $\begin{array}{l}\text { Centro- } \\
\text { Norte }\end{array}$ & $\begin{array}{c}\text { MT-322 (BR-080): } \\
\text { Bom Jesus do } \\
\text { Araguaia/MT a } \\
\text { Peixoto Azevedo/MT }\end{array}$ & Pavimentação & 419.744 & 233 & $\begin{array}{c}12 \text { a } 16 \\
\%\end{array}$ & Até 2015 \\
\hline Rodoviário & $\begin{array}{l}\text { Centro } \\
\text { Sudeste }\end{array}$ & $\begin{array}{l}\text { BR-364: Jataí/GO a } \\
\text { São Simão/GO }\end{array}$ & $\begin{array}{l}\text { Terceira } \\
\text { Faixa }\end{array}$ & 244.610 & 153 & $\begin{array}{l}16 a \\
24 \%\end{array}$ & Até 2015 \\
\hline Rodoviário & $\begin{array}{l}\text { Centro } \\
\text { Sudeste }\end{array}$ & $\begin{array}{c}\text { GO-020: Goiânia/GO } \\
\text { a Bela Vista de } \\
\text { Goiás/GO }\end{array}$ & $\begin{array}{l}\text { Terceira } \\
\text { Faixa }\end{array}$ & 72.661 & 45 & $\begin{array}{c}8 \mathrm{a} \\
12 \%\end{array}$ & Até 2015 \\
\hline Rodoviário & $\begin{array}{l}\text { Centro } \\
\text { Sudeste }\end{array}$ & $\begin{array}{c}\text { BR-364: Santa Rita } \\
\text { do Araguaia/GO a } \\
\text { Jataí/GO }\end{array}$ & $\begin{array}{l}\text { Terceira } \\
\text { Faixa } \\
\end{array}$ & 308 & 192 & $\begin{array}{c}\text { acima } \\
\text { de } 24 \%\end{array}$ & Até 2015 \\
\hline Rodoviário & $\begin{array}{l}\text { Centro } \\
\text { Sudeste } \\
\end{array}$ & $\begin{array}{c}\text { BR-452: Rio } \\
\text { Verde/GO a } \\
\text { Itumbiara/GO } \\
\end{array}$ & $\begin{array}{l}\text { Terceira } \\
\text { Faixa } \\
\end{array}$ & 301 & 188 & $\begin{array}{l}\text { acima } \\
\text { de } 24 \%\end{array}$ & Até 2015 \\
\hline Rodoviário & $\begin{array}{l}\text { Centro } \\
\text { Sudeste }\end{array}$ & $\begin{array}{c}\text { BR-163: Anel } \\
\text { rodoviário de Campo } \\
\text { Grande/MS }\end{array}$ & Duplica & 142 & 29 & $\begin{array}{c}8 a \\
12 \%\end{array}$ & Até 2015 \\
\hline Rodoviário & $\begin{array}{l}\text { Centro } \\
\text { Sudeste }\end{array}$ & $\begin{array}{c}\text { MS-040: } \\
\text { Brasilândia/MS a } \\
\text { Campo Grande/MS }\end{array}$ & $\begin{array}{l}\text { Construção e } \\
\text { Pavimentação }\end{array}$ & 920.920 & 322 & $\begin{array}{c}8 a \\
12 \%\end{array}$ & $\begin{array}{c}2016 a \\
2019\end{array}$ \\
\hline Rodoviário & $\begin{array}{l}\text { Centro } \\
\text { Sudeste }\end{array}$ & $\begin{array}{l}\text { BR-163: Campo } \\
\text { Grande/MS a Nova } \\
\text { Alvorada do Sul/MS }\end{array}$ & Duplicação & 498 & 102 & $\begin{array}{l}\text { acima } \\
\text { de } 24 \%\end{array}$ & Até 2015 \\
\hline Rodoviário & $\begin{array}{l}\text { Centro } \\
\text { Sudeste }\end{array}$ & $\begin{array}{c}\text { BR-163: Campo } \\
\text { Grande/MS a } \\
\text { Sonora/MS }\end{array}$ & Duplicação & 1.709 .814 & 350 & $\begin{array}{c}8 \mathrm{a} \\
12 \%\end{array}$ & $\begin{array}{c}2020 \mathrm{a} \\
2023\end{array}$ \\
\hline Rodoviário & $\begin{array}{l}\text { Centro } \\
\text { Sudeste }\end{array}$ & $\begin{array}{c}\text { BR-050: } \\
\text { Cristalina/GO a } \\
\text { Cumari/GO }\end{array}$ & $\begin{array}{l}\text { Terceira } \\
\text { Faixa }\end{array}$ & 50 & 208 & $\begin{array}{l}12 \mathrm{a} \\
16 \%\end{array}$ & Até 2015 \\
\hline Rodoviário & Leste & $\begin{array}{c}\text { BR-050: } \\
\text { Cristalina/GO a } \\
\text { Cumari/GO }\end{array}$ & $\begin{array}{l}\text { Terceira } \\
\text { Faixa }\end{array}$ & 24 & 11 & $\begin{array}{l}12 \mathrm{a} \\
16 \%\end{array}$ & Até 2015 \\
\hline Rodoviário & ste & $\begin{array}{l}\text { BR-070: Cocalzinho } \\
\text { de Goiás/GO }\end{array}$ & $\begin{array}{l}\text { Terceira } \\
\text { Faixa }\end{array}$ & 78.596 & 49 & $\begin{array}{c}8 \mathrm{a} \\
12 \%\end{array}$ & Até 2015 \\
\hline Rodoviário & Leste & $\begin{array}{l}\text { BR-040: Lusiânia/GO } \\
\text { a Cristalina/GO }\end{array}$ & $\begin{array}{l}\text { Terceira } \\
\text { Faixa }\end{array}$ & 114.846 & 72 & $\begin{array}{l}16 a \\
24 \%\end{array}$ & Até 2015 \\
\hline Rodoviário & Leste & $\begin{array}{c}\text { BR-020: } \\
\text { Formosa/GO a } \\
\text { Guarani de } \\
\text { Goiás/GO }\end{array}$ & $\begin{array}{l}\text { Terceira } \\
\text { Faixa }\end{array}$ & 163.621 & 102 & $\begin{array}{c}\text { Acima } \\
\text { de } 24 \%\end{array}$ & Até 2015 \\
\hline Rodoviár & $\begin{array}{l}\text { Nordeste } \\
\text { Meridional }\end{array}$ & $\begin{array}{l}\text { BR-020: } \\
\text { Formosa/GO a } \\
\text { Guarani de } \\
\text { Goiás/GO }\end{array}$ & $\begin{array}{l}\text { Terceira } \\
\text { Faixa }\end{array}$ & & 147 & $\begin{array}{c}\text { Acima } \\
\text { de } 24 \%\end{array}$ & Até 2015 \\
\hline Total & & & & 5.964 .303 & 7.535 & & \\
\hline
\end{tabular}

Fonte: PNLT (2012).

Org.: A. T. de Santana (2016).

Estudos Geográficos, Rio Claro, 16(2): 106-125, jul./dez. $2018 \quad$ (ISSN 1678 -698X) http://www.periodicos.rc.biblioteca.unesp.br/index.php/estgeo 
Quadro 04 - Portfólio de projetos prioritários do moral hidroviário (PNLT-2012)

\begin{tabular}{|c|c|c|c|c|c|c|c|}
\hline Modal & Vetores & Nome & Tipo & $\begin{array}{l}\text { Invest. } \\
\text { (R\$ mil) }\end{array}$ & $\begin{array}{l}\text { Ext. } \\
(\mathrm{km})\end{array}$ & TIRE & $\begin{array}{l}\text { Período de } \\
\text { Implant. }\end{array}$ \\
\hline Hidroviário & $\begin{array}{l}\text { Centro- } \\
\text { Norte }\end{array}$ & $\begin{array}{c}\text { Hidrovia do } \\
\text { Araguaia-Tocantins - } \\
\text { Pontal do Araguaia } \\
\text { (MT) / Aragarças } \\
(\mathrm{GO})\end{array}$ & Implantação & 1.490 .467 & 1.500 & $\begin{array}{l}16 a \\
24 \%\end{array}$ & Até 2015 \\
\hline Hidroviário & Amazônico & $\begin{array}{l}\text { Hidrovia Teles Pires } \\
\text { - Juruena - Tapajos }\end{array}$ & Implantação & 1.425 .750 & 1.600 & $\begin{array}{c}\text { Acima } \\
\text { de } \\
24 \% \\
\end{array}$ & Até 2015 \\
\hline Total & & & & 2.916.217 & 3.100 & & \\
\hline
\end{tabular}

Fonte: PNLT (2012).

Org.: A. T. de Santana (2016).

\section{Quadro 05 - Portfólio de projetos prioritários do modal ferroviário} (PNLT-2012)

\begin{tabular}{|c|c|c|c|c|c|c|c|}
\hline Modal & Vetores & Nome & Tipo & $\begin{array}{c}\text { Invest. (R\$ } \\
\text { mil) }\end{array}$ & $\begin{array}{l}\text { Ext. } \\
\text { (km) }\end{array}$ & TIRE & $\begin{array}{l}\text { Período de } \\
\text { Implant. }\end{array}$ \\
\hline Ferroviário & $\begin{array}{l}\text { Centro } \\
\text { Sudeste }\end{array}$ & $\begin{array}{c}\text { Ferronorte - } \\
\text { Uberlândia/MG a } \\
\text { Alto Araguaia/MS }\end{array}$ & $\begin{array}{c}\text { Recuperação } \\
\text { e } \\
\text { remodelagem }\end{array}$ & 1.890 .000 & 700 & $\begin{array}{c}8 a \\
12 \%\end{array}$ & Até 2015 \\
\hline Ferroviário & $\begin{array}{c}\text { Centro } \\
\text { Sudeste }\end{array}$ & $\begin{array}{c}\text { Ligação Ferroviária } \\
\text { - Corumbá/MT a } \\
\text { Santos/SP } \\
\end{array}$ & $\begin{array}{c}\text { Recuperação } \\
\text { e } \\
\text { remodelagem }\end{array}$ & 1.890 .000 & 1.275 & $\begin{array}{c}8 \mathrm{a} \\
12 \%\end{array}$ & Até 2015 \\
\hline Ferroviário & Leste & $\begin{array}{c}\text { Ligação EF-354 - } \\
\text { Campinorte/GO - } \\
\text { Macaé/RJ }\end{array}$ & Construção & 7.348 .500 & 1.633 & $\begin{array}{c}8 a \\
12 \%\end{array}$ & 2016 a 2019 \\
\hline Total & & & & 11.128 .500 & 1.975 & & \\
\hline
\end{tabular}

Fonte: PNLT (2012).

Org.: A. T. de Santana (2016).

Retomando o viés interpretativo argumenta-se que o PNLT não está desvinculado das dinâmicas econômicas e políticas em operação no território. Castillo (2011, p. 344), por exemplo, ao analisar a estruturação de uma agricultura globalizada no Cerrado brasileiro e o papel da logística para garantir eficiência organizacional a essa atividade econômica argumenta que a produção competitiva de commodities está num território desprovido de "[...] sistemas logísticos (infraestruturas, equipamentos e organização) que atendam às demandas de uma circulação corporativa [...]". Isso mobiliza o poder público e os setores ligados ao planejamento no sentido de pensar as prioridades de investimentos para solucionar a questão. Nas palavras do autor:

$\mathrm{Na}$ esfera federal, o "Plano Plurianual" (2008-2011), o "Programa de Aceleração do Crescimento" (2007-2010) e o

Estudos Geográficos, Rio Claro, 16(2): 106-125, jul./dez. $2018 \quad$ (ISSN 1678 -698X) http://www.periodicos.rc.biblioteca.unesp.br/index.php/estgeo 
Circulação e desenvolvimento regional...

"Plano Nacional de Logistica e Transportes" (2008-2023) podem revelar, em suas intenções e na lista de investimentos em infraestrutura, o comprometimento do Estado com a fluidez do território para algumas categorias de produtos e de agentes. (CASTILLO, 2011, p. 344-345, aspas do autor).

Os recursos metodológicos utilizados na elaboração do PNLT permitem problematizar a questão levantada por Castillo (2011). Ao definir as matrizes de Origem-Destino um conjunto de produtos relevantes foi selecionado no Sistema de Contas Nacionais (SCN) do IBGE, que é uma classificação de produtos e atividades integradas à Classificação Nacional de Atividades Econômicas (CNAE). De uma lista de 110 produtos apenas 20 foram utilizados na matriz OD do grupo 1 de produtos, entre eles destacam-se: o milho em grão, a cana-deaçúcar, a soja em grão, o produtos da exploração florestal e da silvicultura, o petróleo e o gás natural,o minério de ferro, entre outros.

A construção das matrizes de O-D contribuiu tanto na definição dos Vetores Logísticos, quanto no estudo de viabilidade econômica dos projetos de infraestrutura. Ao justificar a seleção desses produtos como os mais relevantes para o estudo, as seguintes características foram apontadas:

São produtos geradores de grandes volumes de transporte; Têm produção e/ou consumo concentrados em locais ou regiões identificadas; Têm como característica física grande grau de homogeneidade na maior parte das regiões onde são produzidos; Têm características que permitem a utilização de transporte multimodal para sua movimentação; Possuem arquivos de informação disponíveis que possibilitam a execução de análises e estimativas de matrizes O-D; Utilizam equipamentos de transporte a eles adaptados, permitindo ocupação total de sua capacidade (PNLT, 2012, p. 65).

A partir do esclarecimento fica evidente a intencionalidade do PNLT de buscar soluções logísticas infraestruturais para o transporte de grandes volumes de cargas, em regiões onde há forte concentração da produção. Em outras palavras, os produtos relevantes selecionados orientaram a metodologia utilizada no PNLT, beneficiando alguns agentes e regiões produtoras. Isso explica, em partes, a quantidade dos valores dos projetos prioritários destinados à região Centro-Oeste (cerca de 20\%), que concentra a maior produção de commodities agrícolas do país.

Lima (2015, p. 96) também faz importantes indicações acerca do PNLT em sua pesquisa sobre o uso corporativo do território pelo agronegócio em Mato Grosso através da exploração da infraestrutura logística. Para o autor os investimentos públicos e privados destinados ao Centro-Oeste são direcionados aos territórios dominados pelo agronegócio, sendo que "grandes porções da região [ficam] com as condições de infraestrutura aquém das necessidades, tornando-se pouco atrativas para receber certos investimentos". Isso porque há um "alinhamento de interesses" entre o setor público e o setor privado, que selecionam as melhores áreas para investirem na infraestrutura e

Estudos Geográficos, Rio Claro, 16(2): 106-125, jul./dez. $2018 \quad$ (ISSN 1678-698X) http://www.periodicos.rc.biblioteca.unesp.br/index.php/estgeo 
nos serviços, criando redes e nós extremamente necessários e eficientes à estruturação do setor.

No que se refere ao PNLT, Lima (2015) argumenta que um dos principais mecanismos de fomentar essa seletividade da aplicação dos recursos é a Taxa Interna de Retorno Econômico (TIRE). Segundo o autor:

É importante frisar que um dos aspectos norteadores da seleção dos projetos prioritários é 0 seu potencial econômico. Assim, as Taxas Internas de Retorno Econômico (TIRE) devem oferecer uma margem que justifique os investimentos. O mínimo esperado para uma área prioritária é de $8 \%$, mas é possível notar que o índice aumenta na medida em que convergem para as áreas mais dinâmicas, notadamente grandes áreas produtoras e corredores de exportação (LIMA, 2015, p. 98).

É possível constatar a afirmação de Lima (2015) nos quadros 03, 04 e 05. Rodovias como a BR-364, BR-452, BR-163 e BR-050, com TIRE entre 16 a $24 \%$ ou acima de $24 \%$ são bastante funcionais aos complexos agroindustriais instalados na região Centro-Oeste. Da mesma forma, podem ser consideradas rotas de escoamento da produção, ou componentes de "corredores de exportação". No mesmo sentido verificam-se as Taxas de Internas de Retorno Econômico dos projetos hidroviários.

Com o cenário identificado é prudente questionar: as ações previstas no Plano Nacional de Logística e Transporte representam uma política de planejamento que tenciona combater as desigualdades regionais no país? Conforme abordado inicialmente um dos atuais problemas dos estudos de ordenamento territorial consiste na configuração de uma nova diferenciação regional entre "as regiões dinâmicas e competitivas a partir da articulação com o mercado mundial em contraposição com regiões e lugares não-competitivos", que enfrentam um processo de diferenciação pautado no distanciamento econômico e no aprofundamento dos problemas sociais.

A lógica de estruturação de regiões competitivas, assunto abordado também por Castillo (2011), tem contribuído para o agravamento das desigualdades regionais. Pelo que tudo indica, as intervenções propostas pelo PNLT mediante os projetos prioritários analisados não caminham para solucionar ou minimizar este problema. Se voltar aos princípios fundamentais que orientaram a elaboração do plano verificar-se-á que a busca pelo "aumento da competitividade das empresas e das regiões" é almejada pelos técnicos e órgãos governamentais que formularam o documento.

\section{CONSIDERAÇÕES FINAIS}

Os apontamentos e as análises empreendidas permitiram trafegar pela dimensão teórico-metodológica do planejamento no Brasil. Isso possibilitou abordar mudanças de perspectiva paradigmáticas na forma como o Estado e os diferentes atores sociais lidam com a temática do território e do desenvolvimento. Temas que envolvem o projeto nacional, a inserção dependente do país na dinâmica econômica mundial e a atenção ao combate à

Estudos Geográficos, Rio Claro, 16(2): 106-125, jul./dez. 2018 (ISSN 1678-698X) http://www.periodicos.rc.biblioteca.unesp.br/index.php/estgeo 
Circulação e desenvolvimento regional...

desigualdade social foram ancoradouros para ações de planejamento, orquestradas pelo Estado nacional em parcerias com agentes políticos e econômicos.

De forma complementar e interrelacionada também se procedeu com o diagnóstico do Plano Nacional de Transporte e Logística, a fim de perceber os sentidos político-territoriais que orientam as ações do Estado brasileiro para com o planejamento dos transportes, ou da logística espacial do território. Verificou-se que na perspectiva da formação da sociedade brasileira o PNLT situa-se num período marcado pelo chamado "neodesenvolvimentismo", cuja narrativa assenta-se na retomada dos investimentos estatais como estratégia de promoção do crescimento econômico e combate as desigualdades sociais.

Orientado por um viés crítico, o trabalho verificou os discursos presentes no PNLT mediante o rigor analítico e colaboração de diferentes estudos de pesquisadores dedicados aos temas do planejamento e da logística de transportes no território brasileiro, como Araújo (1999), Castillo (2011), Rocha Neto (2013), Lima (2015), Bastos (2016) entre outros. Uma ideia central transcorreu deste esforço: o PNLT, apesar de situar-se numa período da formação social brasileira em que as ações estatais buscavam atacar os problemas sociais do país, entre seus objetivos, sua metodologia, abordagem territorial e previsão de investimentos reconhece-se uma perspectiva de aprofundamento das desigualdades regionais no país, por conta de uma intencionalidade que privilegia a inserção competitiva de determinadas regiões na dinâmica do mercado internacional.

O problema identificado está presente não apenas no discurso do PNLT, mas também se revela nos atores que participaram da sua elaboração. Empresas privadas (Consórcio Logit-Gistran), órgãos governamentais (Secretaria de Política Nacional de Transportes) e instituições de classe (Confederação da Agricultura e Pecuária do Brasil, Confederação Nacional da Indústria, Confederação Nacional do Transporte) contribuíram diretamente com a organização do documento, todavia, considera-se que o diálogo com a sociedade não ocorreu de forma ampla e democrática. Em essência, os investimentos previstos no documento são direcionados a setores hegemônicos da economia, como o agronegócio, a mineração e as atividades industriais de grande porte, que necessitam de corredores de escoamento e exportação.

No caso específico do Centro-Oeste brasileiro os projetos com maior "viabilidade econômica", listados nos quadros 01, 02 e 03, testemunham a intencionalidade de captura do poder de intervenção estatal, ou do dinheiro público, para o atendimento de setores econômicos e regiões profundamente articuladas à lógica de exportações de commodities. Projetos que abarcam rodovias como a BR-364, BR-452, BR-163, BR-050 e BR-020 e as hidrovias Araguaia-Tocantins e Teles Pires-Tapajos, classificados com altas taxas de retorno econômico (TIRE) - portanto prioritários na destinação de recursos públicos, compõem as rotas da nova logística espacial que aprofunda a internacionalização do Cerrado.

Orientado para a integração e/ou fortalecimento de regiões competitivas (CASTILLO, 2011), o PNLT se mostra como poderoso instrumento a serviço do uso corporativo do território (SANTOS; SILVEIRA, 2001). Tal

Estudos Geográficos, Rio Claro, 16(2): 106-125, jul./dez. $2018 \quad$ (ISSN 1678 -698X) http://www.periodicos.rc.biblioteca.unesp.br/index.php/estgeo 
diagnóstico reforça a necessidade de problematização dos estudos que versam a análise das redes de transportes, ou das redes técnicas de uma forma geral. Conforme argumenta Castilho (2014), ao contrário da recorrente naturalização das redes técnicas, urgente se faz retomar uma abordagem que revele seus sentidos políticos, ou seja, o seu papel enquanto instrumento que permite 0 controle e o domínio do território.

\section{REFERÊNCIAS}

ARAÚJO, Tânia Bacelar de. Por uma política nacional de desenvolvimento regional. Revista Econômica do Nordeste, Fortaleza, v. 30, n. 2, p. 144-161, abr.-jun. 1999.

BASTOS, Leila Sobreira. A organização do agronegócio em Goiás: abordagens a partir do Plano Nacional de Logística e Transportes. Geosaberes, Fortaleza, v. 6, número especial (2), p. 492 - 505, Fevereiro. 2016.

BRASIL. Centro de Excelência em Engenharia dos Transportes. Ministério dos Transportes. Ministério da Defesa. Plano Nacional de Logística e Transporte: relatório final. Brasília, 2012.

CASTILHO, Denis. Modernização territorial e redes técnicas em Goiás. 2014. 221 f. Tese (Doutorado) - Instituto de Estudos Socioambientais, Universidade Federal de Goiás, Goiânia, 2014.

CASTILLO, Ricardo. Agricultura globalizada e logística nos cerrados brasileiros. In: SILVEIRA, Márcio Rogério (Org.). Circulação, transportes e logísticas: diferentes perspectivas. São Paulo: Outras Expressões, 2011. cap. 10 , p. 331-354.

FERNANDES, Florestan. Capitalismo dependente e classes sociais na América Latina. 2. ed. Rio de Janeiro: Zahar Editores, 1975.

IANNI, Octávio. Estado e planejamento econômico no Brasil. 6. ed. Rio Janeiro: Civ. Brasileira, 1996.

LIMA, Ronei Coelho de. O uso corporativo do território pelo agronegócio e a questão da logística de transportes em Mato Grosso. 278f. Tese (Doutorado - Doutorado em Geografia), Universidade de Brasília, Brasília, 2015.

MAIA GOMES, Gustavo. Políticas de desenvolvimento regional no mundo contemporâneo. Rio de Janeiro: CNI, 1993.

REZENDE, Fernando. Planejamento no Brasil: auge, declínio e caminhos para a reconstrução. Brasília, DF: CEPAL. Escritório no Brasil/ IPEA, 2010.

Estudos Geográficos, Rio Claro, 16(2): 106-125, jul./dez. $2018 \quad$ (ISSN 1678-698X) http://www.periodicos.rc.biblioteca.unesp.br/index.php/estgeo 
ROCHA NETO, João Mendes. O território no Plano Nacional de Logística e Transportes. In: STEINBERGER, Marília. (Org.). Território, Estado e políticas públicas espaciais. Brasília: Ler Editora, 2013.

SANTOS, Milton; SILVEIRA, María Laura. O Brasil: território e sociedade no início do século XXI. Rio de Janeiro: Record, 2001.

VAINER, Carlos. Regionalismos Contemporâneos. In: em Perspectiva: ensaios selecionados. São Paulo: FUNDAP, 1995.

A Federação

Artigo submetido em: 04/11/2018 Aceito para publicação em: 17/05/2018

Publicado em: 14/12/2018

Estudos Geográficos, Rio Claro, 16(2): 106-125, jul./dez. $2018 \quad$ (ISSN $1678-698 X)$ http://www.periodicos.rc.biblioteca.unesp.br/index.php/estgeo 